\title{
TNFR1 Signaling Contributes to T Cell Anergy During Staphylococcus aureus Sepsis
}

\author{
Camila Ledo ${ }^{1,2,3}$, Cintia D. Gonzalez ${ }^{1,2}$, Carolina V. Poncini ${ }^{1,2}$, Marta Mollerach ${ }^{4,5}$ and \\ Marisa I. Gómez ${ }^{1,2,3 *}$ \\ ${ }^{1}$ Instituto de Investigaciones en Microbiología y Parasitología Médica, Consejo Nacional de Investigaciones Científicas y \\ Tecnológicas, Universidad de Buenos Aires, Buenos Aires, Argentina, ${ }^{2}$ Departamento de Microbiología, Parasitología e \\ Inmunología, Facultad de Medicina, Universidad de Buenos Aires, Buenos Aires, Argentina, ${ }^{3}$ Departamento de \\ Investigaciones Biomédicas y Biotecnológicas, Centro de Estudios Biomédicos, Biotecnológicos, Ambientales y de \\ Diagnóstico, Universidad Maimónides, Buenos Aires, Argentina, ${ }^{4}$ Cátedra de Microbiología, Facultad de Farmacia y \\ Bioquímica, Universidad de Buenos Aires, Buenos Aires, Argentina, ${ }^{5}$ CONICET, Buenos Aires, Argentina
}

OPEN ACCESS

Edited by:

Charles Robert Brown,

University of Missouri, United States

Reviewed by:

Bindu Sukumaran,

Novartis Institutes for BioMedical Research, United States

Huafeng Wang,

California Institute for Biomedical

Research, United States

${ }^{*}$ Correspondence:

Marisa I. Gómez

gomez.marisa@maimonides.edu

Received: 10 May 2018

Accepted: 12 July 2018

Published: 03 August 2018

Citation:

Ledo C, Gonzalez CD, Poncini CV,

Mollerach M and Gómez MI (2018) TNFR1 Signaling Contributes to T Cell Anergy During Staphylococcus aureus

Sepsis.

Front. Cell. Infect. Microbiol. 8:259.

doi: 10.3389/fcimb.2018.00259
Early research on sepsis has focused on the initial hyper-inflammatory, cytokine mediated phase of the disorder whereas the events that govern the concomitant and subsequent anti-inflammatory compensatory response are not completely understood. In this context, the putative participation of TNFR1-mediated signaling in the immunosuppressive phase of Staphylococcus aureus sepsis has not been elucidated. The aim of this study was to determine the role of TNFR1 in directing the immune dysfunction during $S$. aureus sepsis and the potential contribution of MDSC to this process. Using a model of sepsis of peritoneal origin and tnfr $1^{-/-}$mice, we demonstrated that during staphylococcal sepsis $\mathrm{CD}^{+} \mathrm{T}$ cell anergy is significantly dependent on TNFR1 expression and that signaling through this receptor has an impact on bacterial clearance in the spleen. MDSC played a major role in the generation of anergic $\mathrm{CD}^{+}{ }^{+} \mathrm{T}$ cells and their accumulation in the spleen during $S$. aureus sepsis correlated with IL-6 induction. Although TNFR1 signaling was not required for MDSC accumulation and expansion in the spleen, it determined the in vivo expression of Arginase 1 and iNOS, enzymes known to participate in the suppressive function of this population. Moreover, our data indicate that TNFR1-mediated IL-10 production may modulate MDSC function during staphylococcal sepsis. Taken together these results indicate that TNFR1 plays a critical role on T cell dysfunction during S. aureus sepsis by regulating immunomodulatory mediators in MDSC. The role of TNFR1-mediated signaling during the immunosuppressive phase of staphylococcal sepsis should be considered when designing novel alternative therapeutic approaches.

Keywords: TNFR1, Staphylococcus aureus, sepsis, MDSC, anergy, T cell

\section{INTRODUCTION}

Sepsis is a major public health issue and despite improved patient management and supportive care it remains as the leading cause of death in the intensive care units with an estimation of 15-30 million cases worldwide every year (Adhikari et al., 2010; Mayr et al., 2014; Delano and Ward, 2016; Fleischmann et al., 2016) and an incidence of 450 per 100,000 inhabitants (Fleischmann et al., 2016) with nearly $20 \%$ mortality rate. The etiology of sepsis has been changing over the last 
decades with a raising incidence of the gram positive cocci Staphylococcus aureus (Sampedro and Bubeck Wardenburg, 2017). The origin of sepsis can be related to hospital interventions as well as to complications of community-acquired infections that become invasive. In this context, the high incidence of methicillin resistant isolates, from hospital and community environments, have added complexity to the situation.

Early research on sepsis has focused on the initial hyperinflammatory, cytokine mediated phase of the disorder (Opal et al., 1997; Abraham et al., 1998; van Dissel et al., 1998). More recent findings indicate that, although in the beginning of sepsis the balance favors an inflammatory profile (Powers and Bubeck Wardenburg, 2014), anti-inflammatory responses are initiated during the hyper-inflammatory phase leading to subsequent immunosuppression (Tang et al., 2010; Boomer et al., 2014). These varying states of immune paralysis are characterized by impaired immune surveillance and the development of persistent, recurrent, secondary, and nosocomial infections which facilitate protracted events that often lead to death in patients that have survived the initial period of sepsis (Monneret et al., 2011; Otto et al., 2011).

The events that govern immunosuppression during sepsis are not completely elucidated. Moreover, the role that TNF$\alpha$ signaling might have in modulating the anti-inflammatory response has not been determined. Myeloid derived suppressor cells (MDSC) have been described as an immature population of cells that is able to suppress $\mathrm{T}$ cell responses in polymicrobial sepsis and during chronic and persistent $S$. aureus infections (Heim et al., 2014; Tebartz et al., 2015) and it has been described that TNF- $\alpha$ participates in their accumulation and activation during chronic inflammation (Sade-Feldman et al., 2013). We have previously shown the ability of $S$. aureus to modulate TNF- $\alpha$ /TNFR1 signaling during local and systemic infections (Gómez et al., 2004; Giai et al., 2013). Therefore, we hypothesize that TNFR1 signaling could have a role in directing the immunosuppression during $S$. aureus sepsis and that MDSC may participate in that response.

\section{MATERIALS AND METHODS}

\section{Bacterial Strains and Culture Conditions}

S. aureus strain FPR3757 (pulsotype USA300, ST8, SCCmec type IV-spa type 008, PVL positive) was provided by Dr. Alice Prince (Columbia University, NY, USA). S. aureus strain Sa30 (ST30, SCCmec type IVc-spa type 019, PVL positive) was previously described (Fernandez et al., 2013). Bacteria were grown on tryptone soy agar (TSA) or tryptone soy broth (TSB). Bacteria were grown at $37^{\circ} \mathrm{C}$ with agitation until an $\mathrm{OD}_{600}$ of 0.8 : washed and suspended in phosphate buffer (PBS).

\section{Animals and Housing}

Mice were obtained from and maintained in the animal facility of the Department of Microbiology, School of Medicine, University of Buenos Aires. All the procedures involving laboratory animals were approved by the Institutional Committee for Use and Care of Laboratory Animal (CICUAL) of the School of Medicine, University of Buenos Aires (Approval numbers 2737/14 and
2865/15) and followed internationally accepted guidelines (National Institutes of Health, 1996). Animals were maintained in a conventional facility, with controlled temperature $(22 \pm$ $1^{\circ} \mathrm{C}$ ), controlled humidity (55\%), a $12: 12 \mathrm{~h}$ light/dark cycle and they were fed ad libitum. Procedures were performed in an experimental room within the mouse facility. Mice were euthanized using $\mathrm{CO}_{2}$. The number of mice required for each experiment was determined based on preliminary experiments and the desired statistical significance. Cumulative data from 2 to 4 independent experiments with small randomly chosen groups (control and experimental groups) of 3 to 6 animals are shown. The weight of the mice used was in accordance with their age. They showed good mobility and no differences in behavior were observed after manipulations. In this work molecular markers were evaluated in live animals and postmortem. The levels of proinflammatory cytokines in plasma from naïve mice were in the range of expected basal levels (IL-6: 0-50 pg/ml; TNF- $\alpha$ : 0-100 $\mathrm{pg} / \mathrm{ml})$.

\section{Mouse Model}

C57BL/6 and TNFR1 deficient ( $\left.t n f r 1^{-/-}\right)$mice (6 weeks old, 18-20 grams) were intraperitoneally inoculated with $200 \mu \mathrm{l}$ of $S$. aureus containing $4 \times 10^{7} \mathrm{CFU}$. The control groups were inoculated with PBS. Blood samples were obtained by puncture of the mandibular vein at different times before and after inoculation. Plasma was stored at $-80^{\circ} \mathrm{C}$ for subsequent IL-10 and IL-6 quantification. The spleen was removed from mice under sterile conditions and single-cell suspensions were prepared by homogenization through a sterile stainless steel mesh. To assess the bacterial load, aliquots of the infected spleen were serial diluted and cultured on TSA plates.

\section{In vivo Depletion of MDSC}

Mice received a single intraperitoneal injection of $5^{\prime}$ Fluorouracil (5FU, $50 \mathrm{mg} / \mathrm{kg}$ ), a dose proven to specifically deplete MDSC without affecting other splenic cell populations (Vincent et al., 2010; Poncini and González-Cappa, 2017), at day 4 postinoculation with $S$. aureus. MDSC depletion was confirmed by flow cytometry analysis after staining spleen cells with antibodies against CD11b, Gr-1, Ly6C, and Ly6G. Mice treated with 5FU evidenced Monocytic/Granulocytic MDSC proportions equivalent to non-infected mice.

\section{Flow Cytometry}

Single-cell suspensions were incubated with fluorescently-labeled $\mathrm{mAbs}$ for $30 \mathrm{~min}$ at $4^{\circ} \mathrm{C}$. The following $\mathrm{mAbs}$ were used: phycoerythrin-labeled anti-CD4, fluorescein isothiocyanatelabeled anti-CD3 (Ligatis), allophycocyanin-labeled anti-CD8, Alexa 488-labeled anti-Gr1, phycoerythrin-cyanin 7-labeled anti-Gr1, phycoerythrin-labeled anti-CD11b, allophycocyaninlabeled anti-Ly6G and phycoerythrin-cyanin 7-labeled antiLy6G (Biolegend). Cells were washed and fixed in $1 \%$ paraformaldehyde. For intracellular staining, cells were cultured in the presence of monensin $(2 \mu \mathrm{M}$; Biolegend) for $5 \mathrm{~h}$. After surface staining, cells were incubated with phycoerythrin-labeled anti-CD11b and phycoerythrin-cyanin 7-labeled anti-Gr1 for $30 \mathrm{~min}$ at $4^{\circ} \mathrm{C}$. Then, the cells were fixed (4\% PFA) and 
permeabilized (PBS, $0.5 \%$ saponin, $10 \%$ FBS). The Abs used were anti-Arginase, anti-iNOS (Santa Cruz Biotechnology), and Alexa488-labeled anti-rabbit IgG-Alexa (Invitrogen). For Foxp3 detection, cells were stained using the $\mathrm{T}$ regulatory (Treg) cell detection kit (Miltenyi Biotec). Cells were acquired on a FACSAria flow cytometer (BD Biosciences) and analyzed using Cyflogic software.

\section{Apoptosis}

The percentage of lymphocytes undergoing apoptosis was determined by flow cytometry using AnV (annexin V)-FITC (Biolegend). The staining was performed according to the manufacturer's instructions.

\section{MDSC Purification}

Positive selection of $\mathrm{Gr}^{+}$cells was performed using microbeads and MACS LS columns (Miltenyi Biotec), according to the manufacturer's protocol. Positively selected cells were passed over a second selection column to increase their purity. Purity of selected cells was $>95 \%$ as verified by flow cytometry. Cell viability was $\geq 95 \%$ as determined by Trypan blue exclusion.

\section{In vitro Proliferation Assay}

Splenocytes were labeled with carboxyfluorescein diacetate succinimidyl ester (CFSE) according to the manufacturer's instructions (Biolegend). Following labeling, splenocytes were cultured in RPMI medium supplemented with $2 \mathrm{mM}$ glutamine, $50 \mu \mathrm{M} 2-\beta \mathrm{ME}, 50 \mu \mathrm{g} / \mathrm{ml}$ gentamicin and $10 \% \mathrm{FBS}$ in triplicate in round-bottomed 96 -well plates at $2 \times 10^{5} \mathrm{cell} /$ well $(100 \mu \mathrm{l} /$ well $)$. Cells were cultured with $100 \mu \mathrm{l}$ of complete medium or $100 \mu \mathrm{l}$ of complete medium containing concanavalin A $(5 \mu \mathrm{g} / \mathrm{ml})$ for $72 \mathrm{~h}$ at $37^{\circ} \mathrm{C}$ and $5 \% \mathrm{CO}_{2}$. Cells were then harvested and the supernatant was reserved to $-20^{\circ} \mathrm{C}$ for cytokine quantification. Cells were stained with phycoerythrin-labeled anti-CD4 (Ligatis), allophycocyanin-labeled anti-CD8 (Biolegend). The percentage of $\mathrm{CD}^{+}{ }^{+} \mathrm{T}$ cells and $\mathrm{CD} 8^{+} \mathrm{T}$ cells labeled with CFSE was determined by flow cytometry.

\section{In vitro Suppression Assay}

Splenocytes from naïve mice were labeled with CFSE according to the manufacturer's instructions (Biolegend). Following labeling, splenocytes were cultured with purified MDCS obtained from the spleen of $S$. aureus inoculated mice in 1:0, 1:10, 1:20 (T cells:MDSC) ratio in RPMI medium supplemented with $2 \mathrm{mM}$ glutamine, $50 \mu \mathrm{M}$ 2- $\beta \mathrm{ME}, 50 \mu \mathrm{g} / \mathrm{ml}$ gentamicin and 10\% FBS in round-bottomed 96-well plates. Cells were cultured with complete medium containing concanavalin A $(5 \mu \mathrm{g} / \mathrm{ml})$ for $72 \mathrm{~h}$ at $37^{\circ} \mathrm{C}$ and $5 \% \mathrm{CO}_{2}$. Cells were then harvested and the supernatant was reserved to $-20^{\circ} \mathrm{C}$ for cytokine quantification. Cells were stained with phycoerythrin-labeled anti-CD4 (Ligatis), allophycocyanin-labeled anti-CD8 (Biolegend). The percentage of $\mathrm{CD}^{+} \mathrm{T}$ cells and $\mathrm{CD}^{+} \mathrm{T}$ cells labeled with CFSE was determined by flow cytometry.

\section{Real-Time Polymerase Chain Reaction}

RNA was isolated using TRIzol Reagent (Invitrogen). Complementary DNA (cDNA) was made from $1 \mu \mathrm{g}$ of RNA using M-MLV Reverse Transcriptase (Promega). The following primers were used for amplification: for mouse Arginase, $5^{\prime}$-GTC CCT AAT GAC AGC TCC TTT C-3' and 5'-CCA CAC TGA CTC TTC CAT TCT T- $3^{\prime}$; for mouse iNOS, $5^{\prime}$-CAC AGC AAT ATA GGC TCA TCC A- $3^{\prime}$ and $5^{\prime}$-GGA TTT CAG CCT CAT GGT AAA C-3'; for mouse S100A8, 5'-GGA AAT CAC CAT GCC CTC TAC AA- $3^{\prime}$ and $5^{\prime}$-ATG CCA CAC CCA CTT TTA TCA CC-3'; for mouse S100A9, 5'-GGA GCG CAG CAT AAC CAC CAT C-3' and 5'-GCC ATC AGC ATC ATA CAC TCC TCA-3' and for mouse glyceraldehyde-3-7phosphate dehydrogenase (GAPDH), 5'-AAC TTT GGC ATT GTG GAA GGG CTC-3' and $5^{\prime}$-ACC CTG TTG CTG TAG CCG TAT TCA-3'. GAPDH was used as a control for standardization.

\section{ELISA}

IL-10, IL-6, and IFN- $\gamma$ were quantified by enzyme-linked immunosorbent assay using matched antibody pairs (BD Biosciences) according to the manufacturer's instructions.

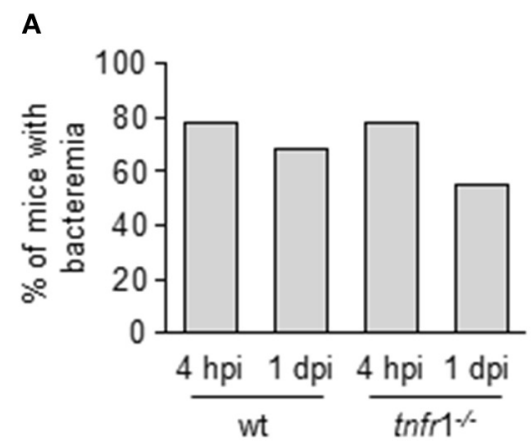

B

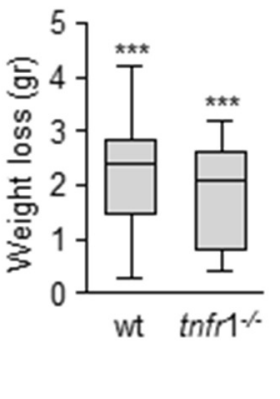

C

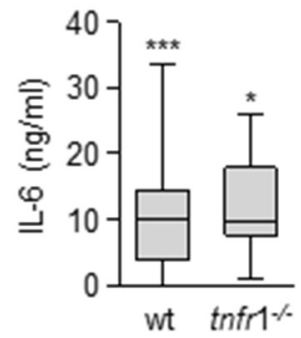

FIGURE 1 | Impact of TNFR1 signaling in the early events after the onset of $S$. aureus sepsis of peritoneal origin. Groups of C57BL/6 wild type and tnfr $1^{-/-}$mice were inoculated with S. aureus FPR3757 by intraperitoneal route. (A) The presence of bacteria in blood were monitored $4 \mathrm{~h}$ and 1 day post-inoculation. Bars represent the percentage of mice with bacteriemia. (B) Weight loss were quantified at day 1 post-inoculation. (C) Plasma levels of IL-6 $4 \mathrm{~h}$ post-inoculation were quantified by ELISA. The levels of IL-6 before inoculation were below the detection limit $(15 \mathrm{pg} / \mathrm{ml})$. (B,C) Boxes and whiskers depict maximum and minimum values obtained from individual mice and the horizontal line represents the median for each group. ${ }^{\star} p<0.05,{ }^{\star \star *} p<0.001$, compared with values obtained from the same group before inoculation, Mann-Whitney $U$-test for nonparametric data. hpi: hours post-inoculation, dpi: days post-inoculation. 

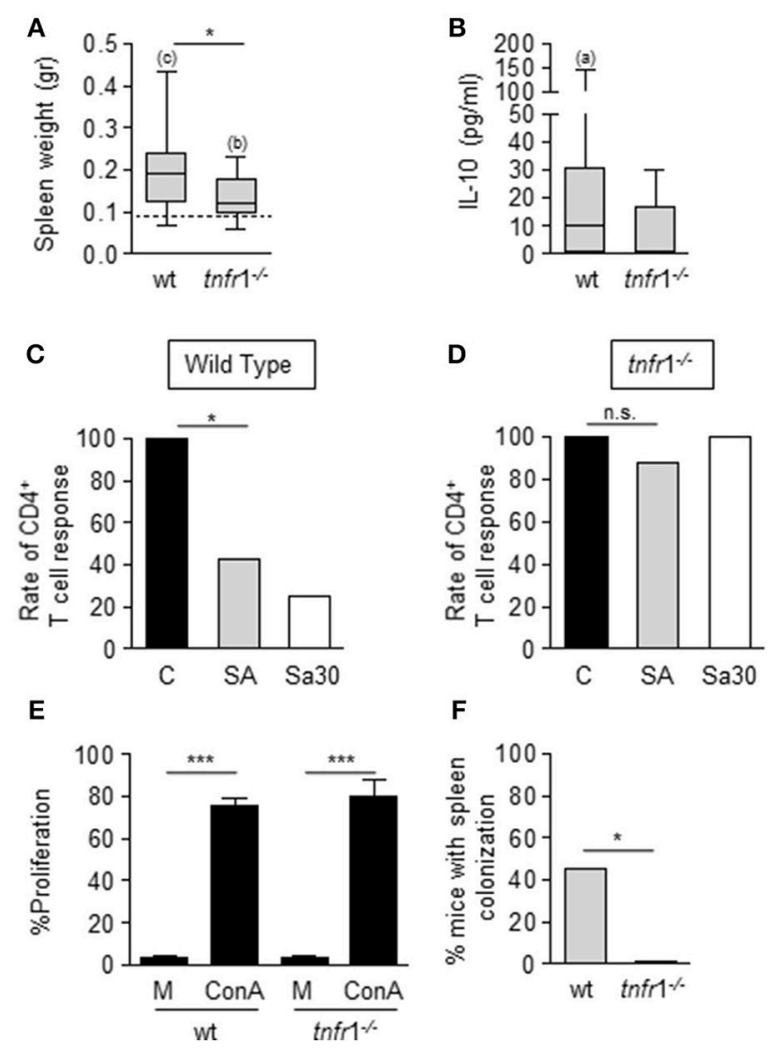

$\mathbf{F}$

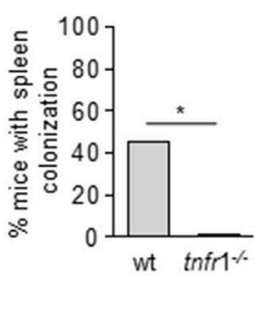

FIGURE 2 | Impact of TNFR1 signaling on the local and systemic host response during $S$. aureus sepsis of peritoneal origin. (A-F) Groups of C57BL/ 6 wild type and tnfr $1^{-/-}$mice were inoculated with $S$. aureus FPR3757 (SA, gray bars and boxes), S. aureus Sa30 (Sa30, white bars) or PBS $(\mathrm{C}$, black bars) by intraperitoneal route. $(\mathbf{A}, \mathbf{B})$ Spleen weight $(\mathbf{A})$ and plasma levels of IL-10 (B) were determined at day 8 post-inoculation. IL-10 was not detected in plasma from mice inoculated with PBS. Boxes and whiskers depict maximum and minimum values obtained from individual mice and the horizontal line represents the median for each group. Dotted line in (A) depicts median value of the PBS group (wild type and tnfr $1^{-/}$combined) ${ }^{*} p<0.05$, (a) $p<0.05$, (b) $p<0.01$, (c) $p<0.001$, (a, b, c) compared with the corresponding groups inoculated with PBS, Mann-Whitney $U$-test for nonparametric data. (C,D) Bars represent the percentage of mice with CD4 $^{+}$ T cells that responded to ConA stimulation (less than 10\% decrease in the proliferative capacity compared with the control group). ${ }^{*} p<0.05$, Fisher's exact test. (E) Splenocytes from mice inoculated with PBS were stimulated with medium or ConA $(5 \mu \mathrm{g} / \mathrm{ml})$. Bars represent the proliferative capacity of $\mathrm{CD}^{+}{ }^{+} \mathrm{T}$ cells in response to medium or ConA stimulation. ${ }^{\star \star *} p<0.001$, Unpaired $t$-test. (F) Bars represent the percentage of mice with spleen colonization at day 8 post-inoculation. ${ }^{*} p<0.05$, Fisher's exact test.

\section{Statistical Analysis}

When comparing two groups of data Student's $t$-test or the nonparametric Mann Whitney $U$-test were used based on the data distribution. The proportions were analyzed using Fisher's exact test. The nonparametric correlation Spearman test was used to analyze the correlation. All the data collected from the experiments were included in the analysis. A $p$-value $<0.05$ was considered statistically significant. GraphPad Prism software was used for statistical analysis.

\section{RESULTS}

\section{T Cell Anergy Induced by S. aureus Is Dependent on TNFR1 Signaling}

In order to understand the role of TNFR1 signaling in the events that govern the immune dysfunction during $S$. aureus sepsis we determined the proliferative capacity of splenic $\mathrm{T}$ cells in the presence or absence of this receptor. The experiments were conducted using a mouse model of $S$. aureus sepsis of peritoneal origin (Ahn et al., 2006; Giai et al., 2013). In this model the onset of sepsis was not dependent on TNFR1 signaling (Figure 1) which allowed to determine the role of this receptor at a later stage. Infection was characterized by a high rate of bacteriemia $4 \mathrm{~h}$ after the inoculation of $S$. aureus (Figure 1A). Bacteria were present in blood $24 \mathrm{~h}$ later (Figure 1A) and cleared by day 4 (data not shown). Significant weight loss was also observed at day 1 (Figure 1B) and a 10\% of mortality that occurred during the first $48 \mathrm{~h}$ was recorded in both the wild type and the $t n f r 1^{-/}$group. In addition, significantly increased levels of IL-6, which have been associated to the severity of sepsis in humans and animal models (Hack et al., 1989; Borrelli et al., 1996; Remick et al., 2002), were found in serum $4 \mathrm{~h}$ post-inoculation (Figure 1C).

At day 8 after inoculation, surviving mice developed splenomegaly with a significant increase in the spleen mass (Figure 2A) and increased levels of IL-10 in serum, characteristic of the immunosuppressive phase of sepsis, were observed (Figure 2B). Interestingly, the splenomegaly was significantly lower in the absence of TNFR1 signaling (Figure 2A) and the levels of circulating IL-10 were also reduced in this group compared with wild type mice (Figure 2B). At this time point, a significant proportion of wild type septic mice showed decreased proliferative rates of $\mathrm{CD}^{+} \mathrm{T}$ cells (Figure 2C) whereas the same population from septic $t n f r 1^{-/-}$mice was responsive to Con A (Figure 2D). The impact of TNFR1 signaling on $\mathrm{T}$ cell anergy did not depend on the staphylococcal strain used as similar results were obtained using the Sa30 clinical isolate for the induction of sepsis (Figures 2C,D). Moreover, we ruled out potential differences in proliferation inherent to the TNFR1 signaling by comparing the ability of $\mathrm{CD}^{+}{ }^{+} \mathrm{T}$ cells from wild type and $t n f r 1^{-/}$mice inoculated with PBS to proliferate in response to ConA (Figure 2E). The increased functionality of $\mathrm{CD}^{+}{ }^{+} \mathrm{T}$ cells from TNFR1 deficient mice correlated with the increased capacity of this group to clear bacteria from the spleen (Figure 2F). Taken together these results indicate that during staphylococcal sepsis CD $4^{+} \mathrm{T}$ cell anergy is significantly dependent on TNFR1 signaling and it may have an impact on bacterial burden in the spleen.

\section{MDSC Modulate T Cell Activity During Staphylococcal Sepsis}

Several mechanisms have been proposed to account for $\mathrm{T}$ cell dysfunction during sepsis. Among them are apoptosis of T cells (Hotchkiss et al., 1999, 2001, 2002; Muenzer et al., 2010), expansion of Treg $\left(\mathrm{CD} 25^{+} \mathrm{CD} 4{ }^{+}\right.$Foxp $3^{+}$) cells (Hotchkiss et al., 2013; Stieglitz et al., 2015) as well as the accumulation of MDSC in peripheral organs (Sander et al., 2010; Cuenca et al., 2011). The viability of $\mathrm{CD}^{+} \mathrm{T}$ cells in the spleen of 


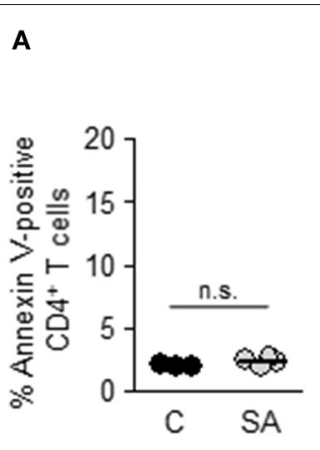

D

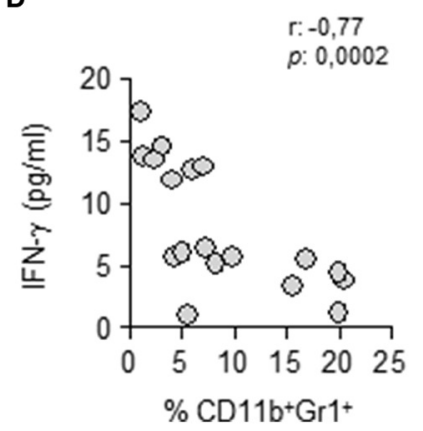

B

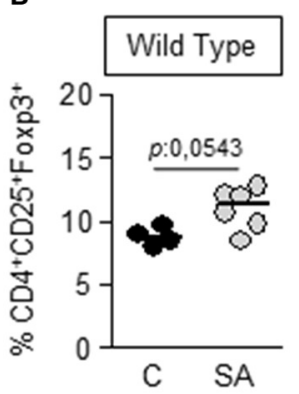

E

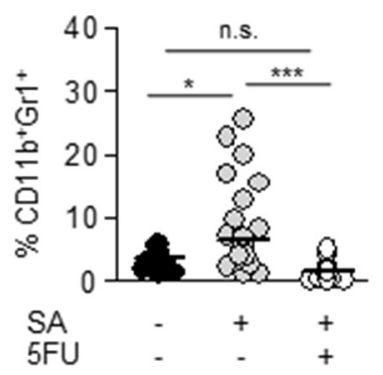

C

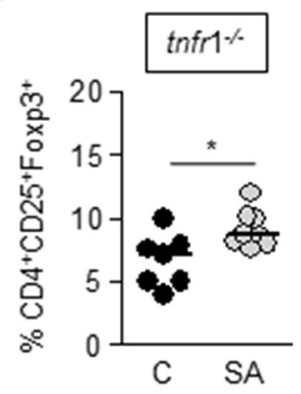

$\mathbf{F}$

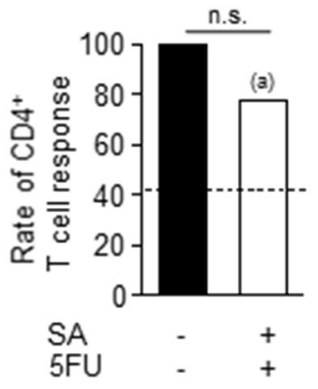

FIGURE 3 | Mechanisms involved in T cell dysfunction during S. aureus sepsis. Groups of C57BL/6 wild type (A,B, D-F) and tnfr1-/- (C) mice were inoculated with S. aureus FPR3757 (SA, gray circles) or PBS (C, black circles and bars) by intraperitoneal route and treated or not with $5 F U$ (50 mg/Kg) (white bar) at day 4 post-inoculation by the same route. (A-C) The percentage of Annexin -positive CD4 $^{+} \mathrm{T}_{\text {cells }}(\mathbf{A})$ and the percentage of Treg cells $\left(\mathrm{CD} 4^{+} \mathrm{CD} 25^{+}\right.$Foxp3 $\left.{ }^{+}\right)$ $\mathbf{( B , C )}$ present in the spleen at day 8 post-inoculation were quantified. Each circle represents an individual mouse and the horizontal lines indicate the median value for each group. ${ }^{*} p<0.05$, Mann-Whitney $U$-test for nonparametric data. (D) Correlation analysis between the levels of IFN- $\gamma$ produced by splenocytes of $S$. aureus inoculated mice in response to ConA and the percentage of $\mathrm{CD} 11 \mathrm{~b}^{+} \mathrm{Gr}{ }^{+}{ }^{+}$cells present in the spleen of each mice at the time of splenocyte isolation. Each circle represent an individual mouse. Data were analyzed using the Spearman test. (E) Percentage of MDSC present in the spleen at day 8 post-inoculation. ${ }^{*} p<0.05$, ${ }^{\star * \star} p<0.001$, Mann-Whitney $U$-test for nonparametric data. (F) Bars represent the percentage of mice whose CD4 ${ }^{+} \mathrm{T}$ cells were able to respond to ConA stimulation (less than 10\% decrease in the proliferative capacity compared with the control group). Dotted line indicates the rate of CD4+ $\mathrm{T}$ cell response in mice inoculated with SA and not treated with 5FU. (a) $p<0.05$, compared with S. aureus inoculated mice not treated with 5FU; n.s. not significant, Fisher's exact test.

infected wild type mice was equivalent to that of the control group (Figure $\mathbf{3 A}$ ) suggesting that apoptosis of $\mathrm{T}$ cells is not a major process at this time point during staphylococcal infection. A small increase in the percentage of Tregs was observed in both wild type and $\operatorname{tnfr} 1^{-/-}$mice at day 8 after inoculation (Figures 3B,C) suggesting a minor role of this population in the TNFR1-dependent T cell anergy. Then, we determined the contribution of MDSC to the S. aureus-induced T cell anergy. The levels of IFN- $\gamma$ produced by splenocytes from wild type infected mice in response to Con A, although they were very variable among animals, showed significant inverse correlation with the percentage of MDSC present in the spleen of wild type septic mice (Figure 3D). To further confirm the role of MDSC on the T cell dysfunction, the expansion of this population was pharmacologically inhibited. Groups of wild type mice were challenged with $S$. aureus and 5-Fluorouracil (5FU), and inducer of MDSC death (Vincent et al., 2010), was administered by intraperitoneal route 4 days later, a time at which bacteria had already colonized the spleen and MDSC started to accumulate in this organ (data not shown). As expected, the percentage and the number of $\mathrm{CD}_{11 b^{+}} \mathrm{Gr}^{+}$cells in the spleen of mice treated with 5-FU was significantly lower than that found in S. aureus infected, non-treated mice and comparable to control non-infected mice
(Figure 3E and data not shown). In the absence of MDSC accumulation the capacity of $\mathrm{CD}^{+} \mathrm{T}$ cells to proliferate in response to Con A was restored (Figure 3F) indicating a major role for MDSC in the generation of anergic $\mathrm{CD} 4^{+} \mathrm{T}$ cells during S. aureus sepsis.

\section{Accumulation of MDSC in the Spleen Is Not Dependent on TNFR1 Signaling}

After demonstrating that both TNFR1 signaling and MDSC are critical in the induction of $\mathrm{T}$ cell anergy during staphylococcal sepsis we evaluated the putative relationship between the signaling mediated by this receptor and MDSC expansion and accumulation in the spleen. A significant accumulation of $\mathrm{CD}_{11 b^{+}} \mathrm{Gr}^{+}$cells in the spleen was observed at day 8 after the onset of sepsis in both wild type and tnfr $1^{-/-}$mice (Figures 4A,B). The absolute number of splenic $\mathrm{CD} 11 \mathrm{~b}^{+} \mathrm{Gr} 1^{+}$ cells in septic mice was 6 -fold the corresponding one in control mice and increased levels of this population were still present in the spleen at day 14 post-inoculation (Figure 4A). Septic $t n f r 1^{-/-}$mice exhibited a similar pattern of MDSC accumulation in the spleen (Figure 4B) indicating that this process is independent of TNFR1 signaling. The relative proportions of cells with monocytic and granulocytic morphology among this 
A

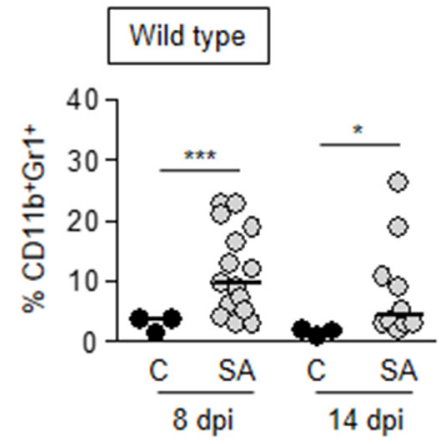

B

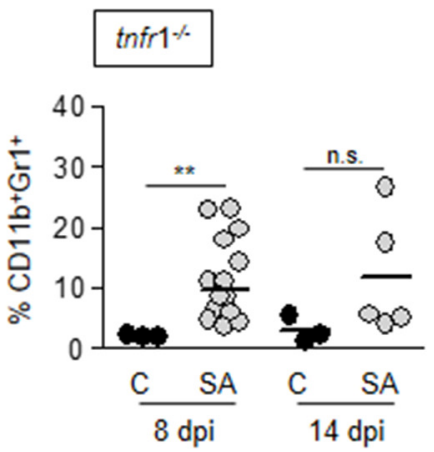

C

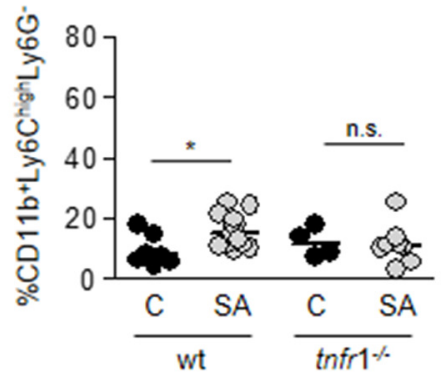

D

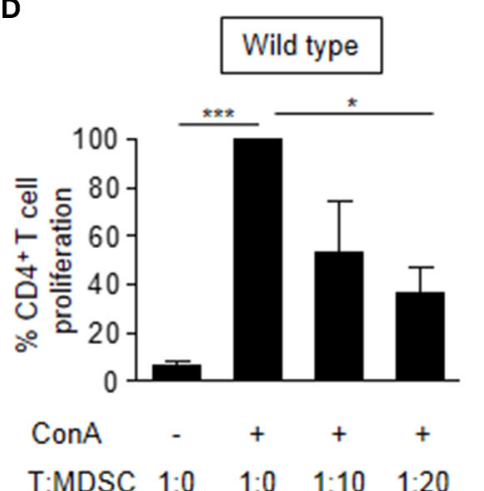

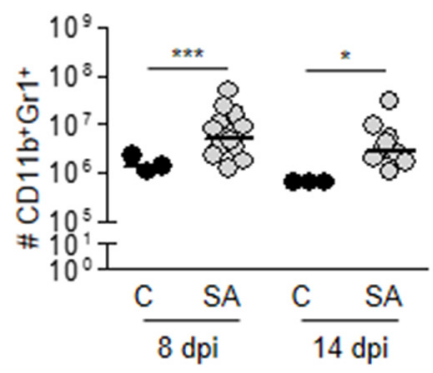
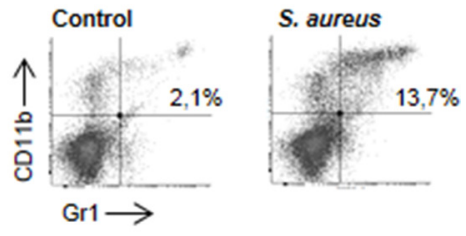
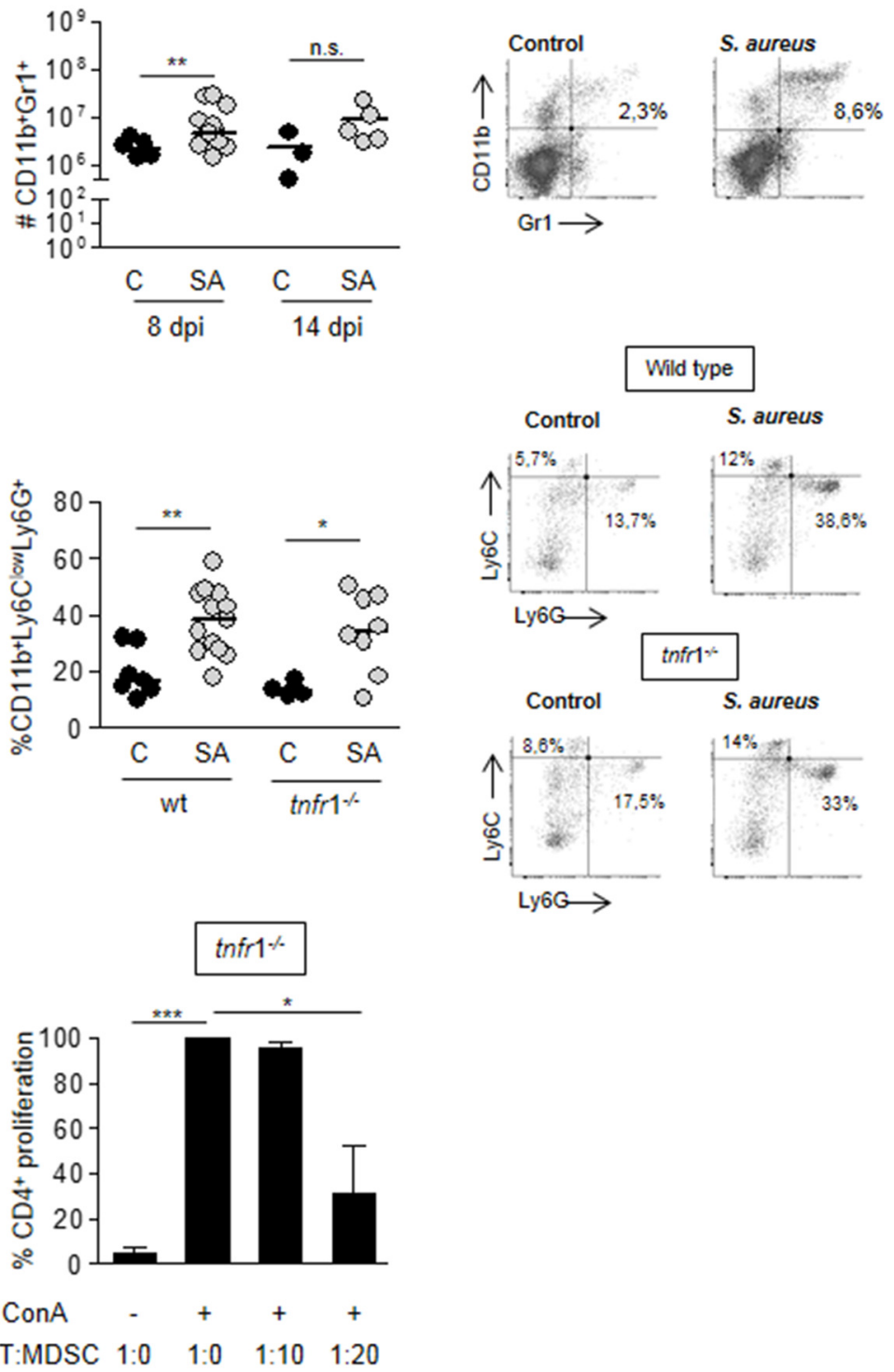

FIGURE 4 | MDSC expansion and accumulation in the spleen during S. aureus sepsis. (A-D) Groups of C57BL/6 wild type (A,C) and thfr $1^{-/-}$(B,C) mice were inoculated with S. aureus FPR3757 (SA, gray circles) or PBS (C, black circles) by intraperitoneal route. (A,B) The percentage and the absolute number of

(Continued) 
FIGURE $4 \mid \mathrm{CD} 11 \mathrm{~b}^{+} \mathrm{Gr} 1+$ cells present in the spleen was determined at days 8 and 14 post-inoculation by staining with specific antibodies and flow cytometry analysis. Representative dot plots and percentages of cells gated as $\mathrm{CD} 11 \mathrm{~b}+\mathrm{Gr} 1^{+}$at day 8 post-inoculation are shown. (C) CD11b, Ly6G, and Ly6C expression was determined in splenocytes at day 8 post-inoculation. Results were calculated after gating on the CD11 b population. Representative dot plots of Ly6G and Ly6C-stained cells and the quantitation of Mo-MDSC: Ly6C ${ }^{\text {high }}$ Ly6G $^{-}$and PMN-MDSC: Ly6C ${ }^{\text {low }}$ Ly6G $^{+}$are shown. ${ }^{*} p<0.05,{ }^{* \star} p<0.01,{ }^{* * \star} p<0.001$, Mann-Whitney U-test for nonparametric data. The quadrants were placed according to the isotype controls. (D) Splenocytes from naive mice were co-cultured with different proportions of $\mathrm{CD} 11 \mathrm{~b}^{+} \mathrm{Gr} 1+$ cells purified from $S$. aureus inoculated mice at day 8 post-challenge and stimulated with ConA (5 $\left.\mu \mathrm{g} / \mathrm{ml}\right)$. Bars represent proliferation of $\mathrm{CD} 4{ }^{+} \mathrm{T}$ cells relative to that observed in the absence of MDSC (considered as $\left.100 \%\right) .{ }^{*} p<0.05,{ }^{* * *} p<0.001$, Unpaired $t$-test.

immature population was determined using the Ly6G and Ly6C surface markers. Granulocytic MDSC were the prevalent phenotype during infection in both wild type and $t n f r 1^{-/}$mice (Figure 4C). The suppressor phenotype of the MDSC expanded and accumulated in the spleen in wild type and $t n f r 1^{-/-}$mice during S. aureus infection was confirmed by determining their capacity to suppress the proliferation of naïve $\mathrm{T}$ cells in response to Con A in vitro (Figure 4D).

Purified MDSC from both wild type and $t n f r 1^{-/-}$mice expressed similar levels of S100A8 and S100A9 (Figures 5A,B) which have a known role in inflammation and directing recruitment of this population (Cheng et al., 2008; Sinha et al., 2008). This is in line with our results that indicate that MDSC recruitment is not dependent of TNFR1 signaling. Among the cytokines that have been proposed to induce MDSC accumulation in tumors is IL-6 (Mundy-Bosse et al., 2011; Tsukamoto et al., 2013; Chen et al., 2014). In the sepsis model, IL6 is early induced during infection (Figure 1C) (Giai et al., 2016) and a significant correlation between the percentage of splenic MDSC and the levels of circulating IL- 6 at the onset of sepsis was observed in both groups of mice (Figure 5C) suggesting that it might be implicated in MDSC accumulation in the spleen.

\section{TNFR1 Signaling Has an Impact in the Expression of Immunomodulatory Mediators by MDSC}

After demonstrating that the $\mathrm{T}$ cell anergy observed during staphylococcal sepsis was dependent on both, TNFR1 signaling and MDSC, but the accumulation of MDSC in the spleen of $\operatorname{tnf} \mathrm{r}^{-/-}$was equivalent to that of wild type mice we hypothesized that TNFR1 signaling could modulate the expression of immunosuppressive mediators in MDSC. These cells are known to exert their suppressive function through the expression of Arginase 1 and iNOS (Trikha and Carson, 2014; Park et al., 2018). Therefore, we evaluated the expression of these enzymes in MDSC purified from the spleen of wild type and $t n f r 1^{-/-}$mice at day 8 after the onset of sepsis. MDSC from wild type septic mice expressed both Arg-1 (Figure 6A) and iNOS (Figure 6B). Conversely, expression levels of these enzymes were low or undetectable in MDSC from $t n f r 1^{-/-}$ mice (Figures 6A,B). The expression of Arginase 1 and iNOS in wild type mice at the protein level was confirmed by intracellular staining and flow cytometry (Figures 6C,D). These results indicate that whereas TNFR1 signaling is not required for MDSC accumulation and expansion in the spleen, it determines the in vivo expression of enzymes known to participate in the suppressive function of this population.
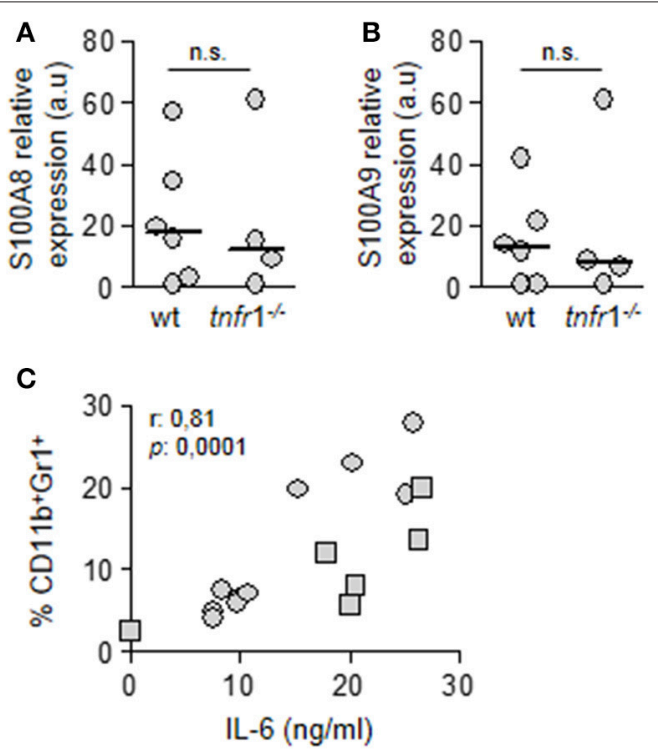

FIGURE 5 | Role of TNFR1 in the accumulation of MDSC in the spleen. Groups of C57BL/ 6 wild type and tnfr $1^{-/-}$mice were inoculated with S. aureus FPR3757 by intraperitoneal route. (A,B) MDSC were purified from the spleen at day 8 post-inoculation. The relative expression levels of S100A8 (A) and S100A9 (B) mRNA in this population were determined by RT real-time PCR and normalized to GAPDH. (a.u.): arbitrary units. Mann-Whitney U-test for nonparametric data. (C) Correlation analysis between plasmatic levels of IL-6 in C57BL/6 wild type (squares) and tnfr $1^{-/-}$(circles) mice $4 \mathrm{~h}$ post-inoculation and the percentage of MDSC present in the spleen at day 8 post-inoculation. Data were analyzed using the Spearman test.

Considering that MDSC from TNFR1 deficient mice showed suppressive activity after in vitro culture in the presence of ConA (Figure 4D), it is suggested that environmental factors in the spleen that are modulated by TNFR1 could be involved in the regulation of Arginase 1 and iNOS expression by MDSC in vivo. Among the factors that could modulate MDSC activity is IL-10 (Pinton et al., 2016; Chen et al., 2017). Therefore, we determined the induction of IL-10 in the spleen of wild type and TNFR1 deficient septic mice. S. aureus infection induced IL-10 in both groups (Figure 7A). However, wild type mice presented significantly increased levels of this cytokine in the spleen compared with $t n f r 1^{-/-}$mice (Figure 7A). Treatment with $5 \mathrm{FU}$ did not impact the overall production of IL-10 (Figure 7B) and the production of this cytokine was not detected in purified MDSC from wild type mice (data not shown) suggesting that although TNFR1 signaling was involved in the induction of this cytokine in response to $S$. aureus, MDSC 

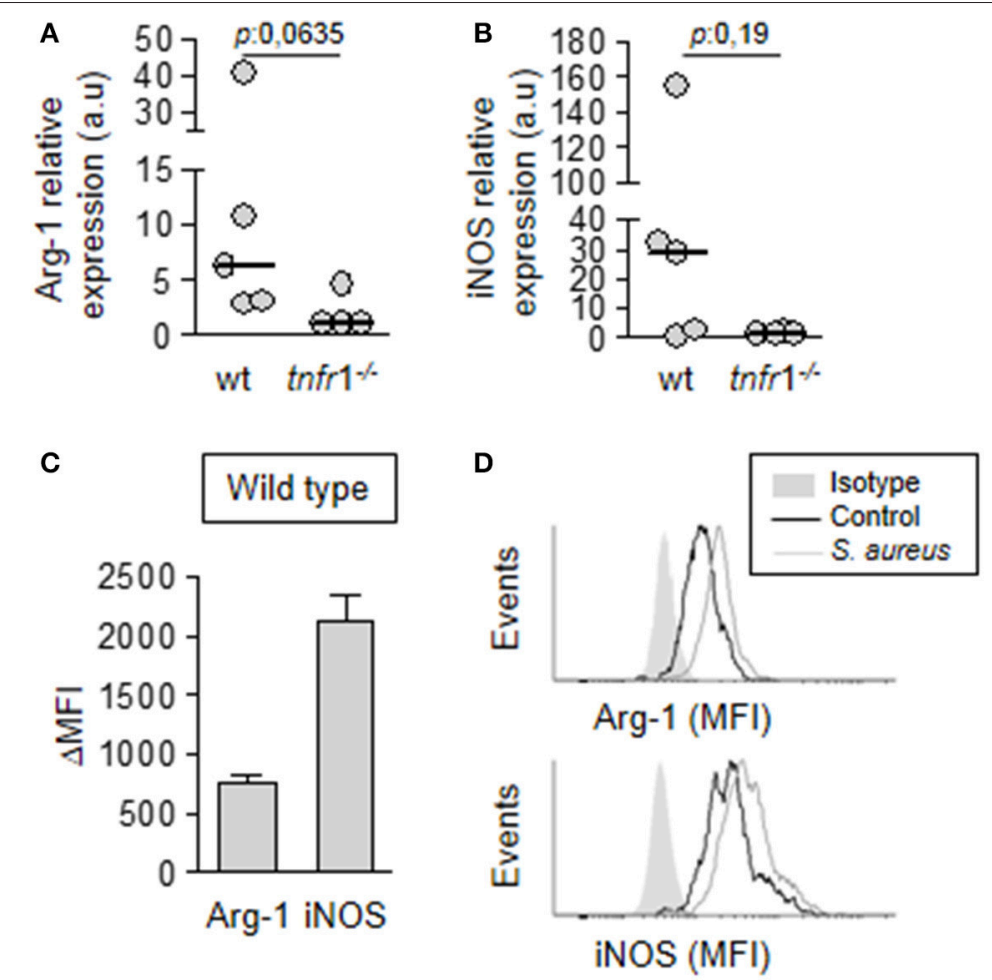

FIGURE 6 | Expression of immunosuppressive mediators by MDSC. Groups of C57BL/6 wild type (A-D) and thfr $1^{-/-}$(A,B) mice were inoculated with S. aureus FPR3757 (SA, gray circles and bars) by intraperitoneal route. (A,B) The MDSC present in the spleen were purified at day 8 post-inoculation and the relative expression of Arg-1 (A) and iNOS (B) in this population was determined by RT real-time PCR and normalized to GAPDH. (a.u.): arbitrary units. Mann-Whitney U-test for nonparametric data. (C,D) The presence of Arginase and iNOS was determined by intracellular staining and flow cytometry in MDSC from wild type mice inoculated with S. aureus or PBS (control). (C) $\triangle \mathrm{MFI}$ : Mean Fluorescence Intensity (MFI) infected - MFI control. (D) Representative histograms are shown.

are not the primary source of IL-10 in the spleen during staphylococcal sepsis. To further investigate the role of IL-10 in the regulation of MDSC activity we quantified the levels of this cytokine in the supernatant of the in vitro co-cultures of MDSC from infected $t n f r 1^{-/-}$mice and näive splenocytes stimulated with ConA as it was shown in Figure 4D. Stimulation of splenocytes with ConA induced the production of IL-10 even in the absence of TNFR1 signaling (Figure 7C) which could explain the suppressive capacity of MDSC during the in vitro co-culture experiments. Therefore, these results suggest that TNFR1-mediated IL-10 production in response to $S$. aureus infection may modulate MDSC function during staphylococcal sepsis rather than TNFR1 direct signaling on MDSC.

\section{DISCUSSION}

S. aureus has emerged as a leading cause of sepsis (Powers and Bubeck Wardenburg, 2014). Through improvements in supportive care measures over the last few decades an increasing percentage of the patients survive through the initial systemic inflammatory period but a significant proportion of the patients eventually succumb to late nosocomial infections (Cuenca and Moldawer, 2012). The high mortality rate of sepsis and the limited clinical success of multiple clinical trials aimed at modulating the host immune response (Russell, 2006) indicate that there is very limited understanding of the complex hostpathogen interactions that take place during this pathology. Although there is a growing consensus that late sepsis-associated morbidities are related to global immunosuppression, the multiple factors that drive the suppressive immune response are not completely elucidated.

In the present study we demonstrated that TNFR1 signaling is critically involved in the development of $\mathrm{T}$ cell anergy during staphylococcal sepsis. To assure that this finding was not unique to the infecting bacterial strain, we used two unrelated isolates, the MRSA USA300 FPR3757 designated as sequence type ST8 and highly epidemic in the United States (Planet, 2017) and the MRSA Sa30 designated as sequence type ST30, the most prevalent clone isolated from invasive community acquired staphylococcal infections in Argentina (Fernandez et al., 2013). TNF- $\alpha$ has been previously linked to $\mathrm{CD}^{+} \mathrm{T}$ cell anergy in HIV infection (Kaneko et al., 1997) and TRAFs, signaling molecules downstream of TNFR1, have also been implicated in defective T cell function (So et al., 2015). During staphylococcal sepsis, $\mathrm{CD} 4^{+} \mathrm{T}$ cell anergy does not seem to be the consequence of direct TNFR1 signaling on T cells because their functionality could be recovered by blocking the expansion of MDSC.

MDSC have been previously linked to $T$ cell anergy and bacterial persistence during chronic S. aureus infection (Heim 


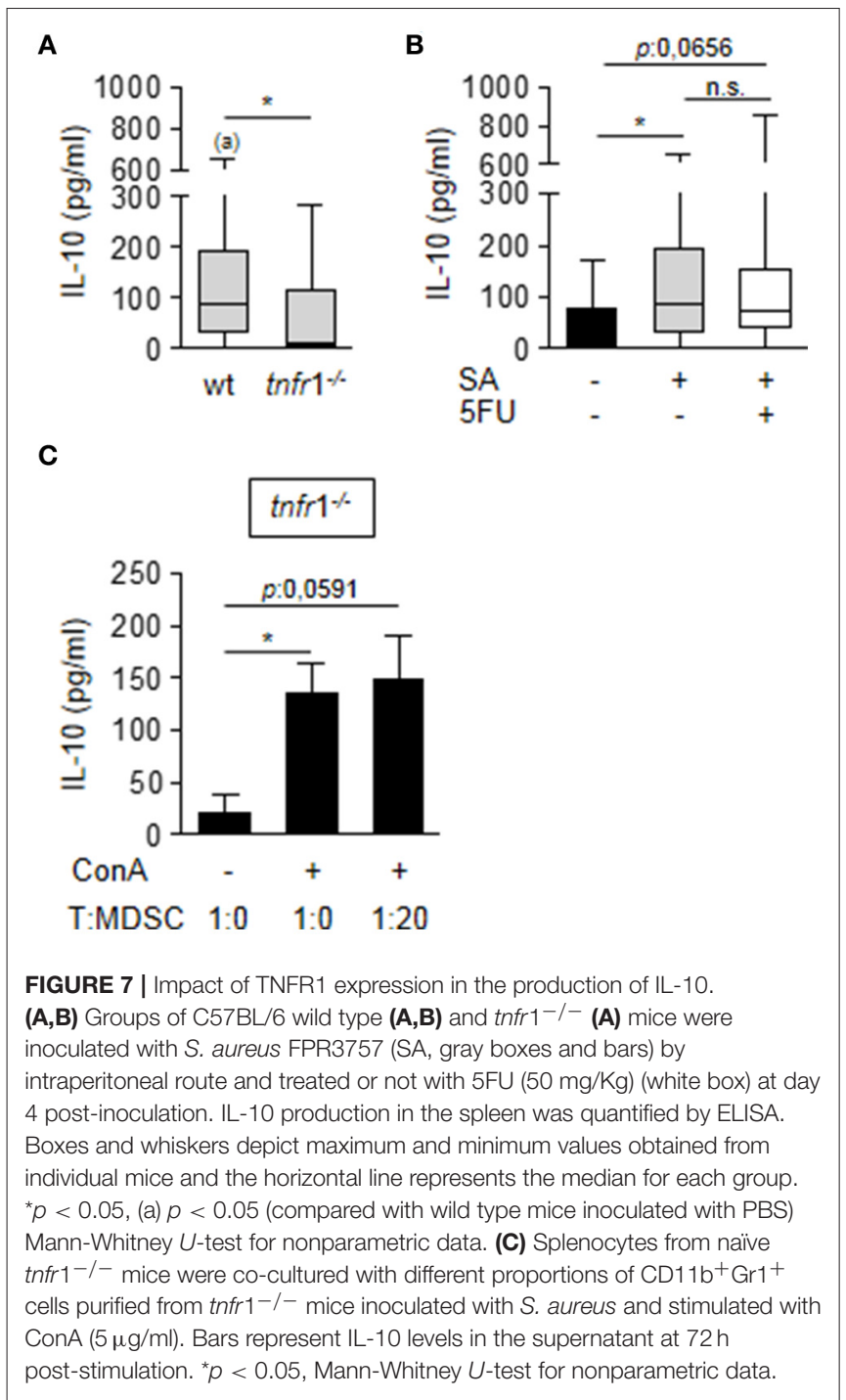

et al., 2014; Tebartz et al., 2015). Moreover, in recent studies conducted with septic patients the expansion of granulocytic MDSC correlated with bad prognosis of the disease regardless of the microorganism involved (Mathias et al., 2017). Our results further confirm that MDSC are major modulators of $\mathrm{T}$ cell activity during staphylococcal sepsis. Moreover, T cell anergy induced by $S$. aureus was accompanied by a heterogeneous production of IFN- $\gamma$ in the spleen and the levels of this cytokine negatively correlated with the percentage of splenic MDSC. This observation might be of clinical interest because it has been shown that administration of IFN- $\gamma$ reversed the adverse sequelae of sepsis induced immunosuppression in patients (Döcke et al., 1997).

Despite the increasing recognition of MDSC as key players in modulating suppressive responses during infection there is very little knowledge of the mechanisms involved in their recruitment, differentiation arrest and acquisition of the immunosuppressive phenotype. TNF- $\alpha$ signaling mediates many of the systemic inflammatory consequences of sepsis (Chousterman et al., 2017). It is also critical for S. aureus clearance (Nakane et al., 1995; Skabytska et al., 2014). Our results in the S. aureus sepsis model, demonstrated that TNF- $\alpha$ signaling through TNFR1 is not required for MDSC expansion and accumulation but it is critical for the expression of MDSC immunosuppressive mediators such as Arginase 1 and iNOS. A two signal model has been proposed for the expansion and function of MDSC in which a first signal is responsible for MDSC expansion and the second one for driving MDSC activation (Condamine and Gabrilovich, 2011). During chronic inflammation induced by mycobacterial antigens, TNF$\alpha$ exhibited a dual function arresting differentiation of immature myeloid cells and augmenting MDSC activity (Sade-Feldman et al., 2013). In tumors, it was proposed that TNF- $\alpha$ signaling through TNFR2 inhibits caspase 8 activity and promotes MDSC survival and accumulation helping tumor cells to evade the immune system (Zhao et al., 2012). More recently the role of TNFR2 in the generation of monocytic MDSC has been demonstrated (Polz et al., 2014). TNFR2 signaling is mainly driven by membrane associated TNF- $\alpha$ whereas TNFR1 signaling is triggered by soluble TNF- $\alpha$ (Cabal-Hierro and Lazo, 2012). We have previously demonstrated that $S$. aureus activates ADAM17, the metalloprotease responsible of cleaving TNF- $\alpha$ from the cell membrane. Moreover, in the sepsis model TNF- $\alpha$ expression is induced in response to S. aureus inoculation (Giai et al., 2013). Therefore, it is not unexpected that TNFR1 signaling will be active during staphylococcal sepsis.

Interestingly, MDSC isolated from $\operatorname{tnfr} 1^{-/-}$septic mice showed intrinsic suppressive capacity when evaluated in vitro, which suggests that mediators locally produced during infection in a TNFR1-dependent manner could modulate their activity in vivo. In line with this hypothesis, recent findings show that locally produced IL-10 is implicated in MDSC activation in an $S$. aureus biofilm infection model (Heim et al., 2015) and in a collagen-induced model of rheumatoid arthritis (Park et al., 2018). The data of our work indicate that during S. aureus sepsis, TNFR1 signaling was critical for systemic and local IL10 induction. This finding could explain the lower expression of Arginase 1 and iNOS, both known immunosuppressive factors, in MDSC from $\operatorname{tnfr} 1^{-/-}$mice compared with MDSC from wild type mice during in vivo infection. Therefore, the microenvironment induced in response to the signaling cascades initiated by TNFR1, which among other putative factors contains IL-10, could provide the "second signal" and determine the activity of MDSC during staphylococcal sepsis. In this regard, it has been established that IL-10 levels are increased in septic patients and that those levels predict mortality (Hotchkiss and Karl, 2003). The source of IL10 in the spleen were not the MDSC as this cytokine was not detected in isolated MDSC and the levels of IL-10 were not affected by blocking the expansion of this population. Thus, it remains to be elucidated the population responsible for TNFR1dependent induction of IL-10.

Regarding the nature of the "first signal" driving the expansion and accumulation of MDSC several studies have demonstrated a positive relationship between increased proportions of MDSC and higher levels of IL-6 (Trikha and Carson, 2014; Chen et al., 2017). Our results show a positive correlation between the levels 
of IL-6 at early times after inoculation and the percentage of MDSC accumulated in the spleen similarly to what it is observed in septic patients in which a positive correlation between MDSC and the levels of IL-6 at the day of admission was found (Darcy et al., 2014).

In previous attempts to understand the events that dictate the immunosuppression during sepsis, a role for Treg cells has been proposed (Hotchkiss et al., 2013; Stieglitz et al., 2015). Moreover, the capacity of MDSC in inducing the expansion of Tregs has been demonstrated (Park et al., 2018). According to our study, the Treg population seems to have, if any, a minor role in the suppression of $\mathrm{CD}^{+} \mathrm{T}$ cell responses during staphylococcal sepsis based on the observation that the expansion of these cells did not correlate with either proper o defective TNFR1 signaling.

$\mathrm{T}$ cell anergy has now been largely recognized as an important component of sepsis-related immunosuppression. However, the signaling pathways induced by different bacterial pathogens that lead to dampened $\mathrm{T}$ cell function are poorly understood. TNFR1 is a central player during $S$. aureus infections. This receptor not only signals TNF- $\alpha$, which is rapidly induced after the entry of the bacteria, but it also recognizes protein $A$, a major staphylococcal surface protein, initiating both pro-inflammatory (Gómez et al., 2004, 2006) and anti-inflammatory cascades (Giai et al., 2013, 2016). The results presented here indicate that during staphylococcal sepsis TNFR1 has a significant impact in modulating $\mathrm{CD} 4^{+} \mathrm{T}$ cell anergy and that function of this receptor is relevant to bacterial clearance in the spleen. Moreover, we demonstrated that TNFR1 signaling induces the microenvironment to sustain MDSC suppressive activity

\section{REFERENCES}

Abraham, E., Anzueto, A., Gutierrez, G., Tessler, S., San Pedro, G., Wunderink, R., et al. (1998). Double-blind randomised controlled trial of monoclonal antibody to human tumour necrosis factor in treatment of septic shock, NORASEPT II study group. Lancet 351, 929-933. doi: 10.1016/S0140-6736(05)60602-2

Adhikari, N. K., Fowler, R. A., Bhagwanjee, S., and Rubenfeld, G. D. (2010). Critical care and the global burden of critical illness in adults. Lancet 376, 1339-1346. doi: 10.1016/S0140-6736(10)60446-1

Ahn, J. Y., Song, J. Y., Yun, Y. S., Jeong, G., and Choi, I. S. (2006). Protection of Staphylococcus aureus-infected septic mice by suppression of early acute inflammation and enhanced antimicrobial activity by ginsan. FEMS Immunol. Med. Microbiol. 46, 187-197. doi: 10.1111/j.1574-695X.2005.00021.x

Boomer, J. S., Green, J. M., and Hotchkiss, R. S. (2014). The changing immune system in sepsis: is individualized immuno-modulatory therapy the answer? Virulence 5, 45-56. doi: 10.4161/viru.26516

Borrelli, E., Roux-Lombard, P., Grau, G. E., Girardin, E., Ricou, B., Dayer, J., et al. (1996). Plasma concentrations of cytokines, their soluble receptors, and antioxidant vitamins can predict the development of multiple organ failure in patients at risk. Crit. Care Med. 24, 392-397. doi: 10.1097/00003246-199603000-00006

Cabal-Hierro, L., and Lazo, P. S. (2012). Signal transduction by tumor necrosis factor receptors. Cell. Signal. 24, 1297-1305. doi: 10.1016/j.cellsig.2012.02.006

Cheng, P., Corzo, C. A., Luetteke, N., Yu, B., Nagaraj, S., Bui, M. M., et al. (2008). Inhibition of dendritic cell differentiation and accumulation of myeloidderived suppressor cells in cancer is regulated by S100A9 protein. J. Exp. Med. 205, 2235-2249. doi: 10.1084/jem.20080132

Condamine, T., and Gabrilovich, D. I. (2011). Molecular mechanisms regulating myeloid-derived suppressor cell differentiation and function. Trends Immunol. 32, 19-25. doi: 10.1016/j.it.2010.10.002 demonstrating the importance of this receptor during the immunosuppressive phase of staphylococcal sepsis. Whether TNFR1 signaling triggered by protein $A$, in addition to TNF- $\alpha$, is critical for MDSC activity remains to be elucidated.

\section{AUTHOR CONTRIBUTIONS}

MG and CL conceived and designed the experiments, analyzed the data and wrote the manuscript. CL, CG, and CP performed the experiments. CG, CP, and MM analyzed the data and critically revised the manuscript. MG procured funding. All authors read and approved the final manuscript.

\section{FUNDING}

This work was supported in part by grants from the Agencia Nacional de Promoción de la Ciencia y la Tecnología, Argentina (ANPCYT PICT 13-1233 to MG); the Secretaría de Ciencia y Técnica, Universidad de Buenos Aires, Argentina (UBACyT 20020110100138BA and 20020150100114BA to MG). Intramural funding has been provided by the Fundación Científica Felipe Fiorellino.

\section{ACKNOWLEDGMENTS}

The authors thank Monica Pomerantz and Lorena Medina for technical assistance. We thank Daniela Ureta, Ariel Billordo, and Plácida Blas for technical assistance with flow cytometry.

Chen, M. F., Kuan, F. C., Yen, T. C., Lu, M. S., Lin, P. Y., Chung, Y. H., et al. (2014). IL-6-stimulated CD11b + CD14+ HLA-DR- myeloid-derived suppressor cells, are associated with progression and poor prognosis in squamous cell carcinoma of the esophagus. Oncotarget. 5, 8716-8728. doi: 10.18632/ oncotarget. 2368

Chousterman, B. G., Swirski, F. K., Weber, G. F. (2017). Cytokine storm and sepsis disease pathogenesis. Semin Immunopathol. 39, 517-528. doi: 10.1007/s00281-017-0639-8

Chen, J., Ye, Y., Liu, P., Yu, W., Wei, F., Li, H., et al. (2017). Suppression of T cells by myeloid-derived suppressor cells in cancer. Hum. Immunol. 78, 113-119. doi: 10.1016/j.humimm.2016.12.001

Cuenca, A. G., Delano, M. J., Kelly-Scumpia, K. M., Moreno, C., Scumpia, P. O., Laface, D. M., et al. (2011). A paradoxical role for myeloidderived suppressor cells in sepsis and trauma. Mol. Med. 17, 281-292. doi: $10.2119 /$ molmed.2010.00178

Cuenca, A. G., and Moldawer, L. L. (2012). Myeloid-derived suppressor cells in sepsis: friend or foe? Intensive Care Med. 38, 928-930. doi: 10.1007/s00134-012-2575-3

Darcy, C. J., Minigo, G., Piera, K. A., Davis, J. S., McNeil, Y. R., Chen, Y., et al. (2014). Neutrophils with myeloid derived suppressor function deplete arginine and constrain $\mathrm{T}$ cell function in septic shock patients. Crit Care. 18, R163. doi: $10.1186 /$ cc14003

Delano, M. J., and Ward, P. A. (2016). The immune system's role in sepsis progression, resolution, and long-term outcome. Immunol. Rev. 274, 330-353. doi: 10.1111/imr.12499

Döcke, W. D., Randow, F., Syrbe, U., Krausch, D., Asadullah, K., Reinke, P., et al. (1997). Monocyte deactivation in septic patients: restoration by IFN-gamma treatment. Nat. Med. 3, 678-681.

Fernandez, S., de Vedia, L., Lopez Furst, M. J., Gardella, N., Di Gregorio, S., Ganaha, M. C., et al. (2013). Methicillin-resistant Staphylococcus 
aureus ST30-SCCmec IVc clone as the major cause of communityacquired invasive infections in Argentina. Infect. Genet. Evol. 14, 401-405. doi: 10.1016/j.meegid.2012.12.018

Fleischmann, C., Scherag, A., Adhikari, N. K., Hartog, C. S., Tsaganos, T., Schlattmann, P., et al. (2016). Assessment of global incidence and mortality of hospital-treated sepsis. current estimates and limitations. Am. J. Respir. Crit. Care Med. 193, 259-272. doi: 10.1164/rccm.201504-0781OC

Giai, C., Gonzalez, C., Ledo, C., Garofalo, A., Di Genaro, M. S., Sordelli, D. O., et al. (2013). Shedding of tumor necrosis factor receptor 1 induced by protein a decreases tumor necrosis factor alpha availability and inflammation during systemic Staphylococcus aureus infection. Infect. Immun. 81, 4200-4207. doi: 10.1128/IAI.00593-13

Giai, C., Gonzalez, C. D., Sabbione, F., Garofalo, A., Ojeda, D., Sordelli, D. O., et al. (2016). Staphylococcus aureus induces shedding of IL-1RII in monocytes and neutrophils. J. Innate Immun. 8, 284-298. doi: 10.1159/000443663

Gómez, M. I., Lee, A., Reddy, B., Muir, A., Soong, G., Pitt, A., et al. (2004). Staphylococcus aureus protein a induces airway epithelial inflammatory responses by activating TNFR1. Nat. Med. 10, 842-848. doi: 10.1038/nm1079

Gómez, M. I., O’Seaghdha, M., Magargee, M., Foster, T. J., and Prince, A. S. (2006). Staphylococcus aureus protein a activates TNFR1 signaling through conserved IgG binding domains. J. Biol. Chem. 281, 20190-20196. doi: 10.1074/jbc.M601956200

Hack, C. E., De Groot, E. R., Felt-Bersma, R. J., Nuijens, J. H., Strack Van Schijndel, R. J., Eerenberg-Belmer, A. J., et al. (1989). Increased plasma levels of interleukin-6 in sepsis. Blood. 74, 1704-1710.

Heim, C. E., Vidlak, D., Scherr, T. D., Kozel, J. A., Holzapfel, M., Muirhead, D. E., et al. (2014). Myeloid-derived suppressor cells contribute to Staphylococcus aureus orthopedic biofilm infection. J. Immunol. 192, 3778-3792. doi: 10.4049/jimmunol.1303408

Heim, C. E., Vidlak, D., and Kielian, T. (2015). Interleukin-10 production by myeloid-derived suppressor cells contributes to bacterial persistence during Staphylococcus aureus orthopedic biofilm infection. J. Leukoc. Biol. 98, 1003-1013. doi: 10.1189/jlb.4VMA0315-125RR

Hotchkiss, R. S., Swanson, P. E., Freeman, B. D., Tinsley, K. W., Cobb, J. P., Matuschak, G. M., et al. (1999). Apoptotic cell death in patients with sepsis, shock, and multiple organ dysfunction. Crit. Care Med. 27, 1230-1251. doi: 10.1097/00003246-199907000-00002

Hotchkiss, R. S., Tinsley, K. W., Swanson, P. E., Schmieg, R. E. Jr, Hui, J. J., Chang, K. C., et al. (2001). Sepsis-induced apoptosis causes progressive profound depletion of B and CD4+ T lymphocytes in humans. J. Immunol. 166, 6952-6963. doi: 10.4049/jimmunol.166.11.6952

Hotchkiss, R. S., Tinsley, K. W., Swanson, P. E., Grayson, M. H., Osborne, D. F., Wagner, T. H., et al. (2002). Depletion of dendritic cells, but not macrophages, in patients with sepsis. J. Immunol. 168, 2493-2500. doi: 10.4049/jimmunol.168.5.2493

Hotchkiss, R. S., and Karl, I. E. (2003). The pathophysiology and treatment of sepsis. N. Engl. J. Med. 348, 138-150. doi: 10.1056/NEJMra021333

Hotchkiss, R. S., Monneret, G., and Payen, D. (2013). Sepsis-induced immunosuppression: from cellular dysfunctions to immunotherapy. Nat. Rev. Immunol. 13, 862-874. doi: 10.1038/nri3552

Kaneko, H., Hishikawa, T., Sekigawa, I., Hashimoto, H., Okumura, K., and Kaneko, Y. (1997). Role of tumour necrosis factor-alpha (TNF-alpha) in the induction of HIV-1 gp120-mediated CD4+ T cell anergy. Clin. Exp. Immunol. 109, 41-46. doi: 10.1046/j.1365-2249.1997.4231325.x

Mathias, B., Delmas, A. L., Ozrazgat-Baslanti, T., Vanzant, E. L., Szpila, B. E., Mohr, A. M., et al. (2017). Human myeloid-derived suppressor cells are associated with chronic immune suppression after severe sepsis/septic shock. Ann. Surg. 265, 827-834. doi: 10.1097/SLA.0000000000001783

Mayr, F. B., Yende, S., and Angus, D. C. (2014). Epidemiology of severe sepsis. Virulence 5, 4-11. doi: 10.4161/viru.27372

Monneret, G., Venet, F., Kullberg, B. J., and Netea, M. G. (2011). ICU-acquired immunosuppression and the risk for secondary fungal infections. Med. Mycol. 49, S17-S23. doi: 10.3109/13693786.2010.509744

Muenzer, J. T., Davis, C. G., Chang, K., Schmidt, R. E., Dunne, W. M., Coopersmith, C. M., et al. (2010). Characterization and modulation of the immunosuppressive phase of sepsis. Infect. Immun. 78, 1582-1592. doi: 10.1128/IAI.01213-09
Mundy-Bosse, B. L., Young, G. S., Bauer, T., Binkley, E., Bloomston, M., Bill, M. A., et al. (2011). Distinct myeloid suppressor cell subsets correlate with plasma IL- 6 and IL-10 and reduced interferon-alpha signaling in CD4 ${ }^{+} \mathrm{T}$ cells from patients with GI malignancy. Cancer Immunol. Immunother. 60, 1269-1279. doi: 10.1007/s00262-011-1029-z

National Institutes of Health (1996). Guide for the Care and Use of Laboratory Animals, Vol. 469. Washington, DC: National Research Council Guide.

Nakane, A., Okamoto, M., Asano, M., Kohanawa, M., and Minagawa, T. (1995). Endogenous gamma interferon, tumor necrosis factor, and interleukin-6 in Staphylococcus aureus infection in mice. Infect. Immun. 63, 1165-1172.

Opal, S. M., Fisher, C. J. Jr, Dhainaut, J. F., Vincent, J. L., Brase, R., Lowry, S. F., et al. (1997). Confirmatory interleukin-1 receptor antagonist trial in severe sepsis: a phase III, randomized, double-blind, placebo-controlled, multicenter trial, the interleukin-1 receptor antagonist sepsis investigator group. Crit. Care Med. 7, 1115-1124. doi: 10.1097/00003246-199707000-00010

Otto, G. P., Sossdorf, M., Claus, R. A., Rödel, J., Menge, K., Reinhart, K., et al. (2011). The late phase of sepsis is characterized by an increased microbiological burden and death rate. Crit Care. 15, R183. doi: 10.1186/cc10332

Park, M. J., Lee, S. H., Kim, E. K., Lee, E. J., Baek, J. A., Park, S. H., et al. (2018). Interleukin-10 produced by myeloid-derived suppressor cells is critical for the induction of Tregs and attenuation of rheumatoid inflammation in mice. Sci. Rep. 8:3753. doi: 10.1038/s41598-018-21856-2

Pinton, L., Solito, S., Damuzzo, V., Francescato, S., Pozzuoli, A., Berizzi, A., et al. (2016). Activated T cells sustain myeloid-derived suppressor cell-mediated immune suppression. Oncotarget 7, 1168-1184. doi: 10.18632/oncotarget.6662

Planet, P.J. (2017). Life After USA300: the rise and fall of a superbug. J. Infect. Dis. 215. S71-S77. doi: 10.1093/infdis/jiw444

Polz, J., Remke, A., Weber, S., Schmidt, D., Weber-Steffens, D., Pietryga-Krieger, A., et al. (2014). Myeloid suppressor cells require membrane TNFR2 expression for suppressive activity. Immun. Inflamm. Dis. 2, 121-130. doi: 10.1002/iid3.19

Poncini, C. V., and González-Cappa, S. M. (2017). Dual role of monocyte-derived dendritic cells in Trypanosoma cruzi infection. Eur. J. Immunol. 47, 1936-1948. doi: 10.1002/eji.201646830

Powers, M. E., and Bubeck Wardenburg, J. (2014). Igniting the fire: staphylococcus aureus virulence factors in the pathogenesis of sepsis. PLoS Pathog. 10:e1003871. doi: 10.1371/journal.ppat.1003871

Remick, D. G., Bolgos, G. R., Siddiqui, J., Shin, J., and Nemzek, J. A. (2002). Six at six: interleukin- 6 measured $6 \mathrm{~h}$ after the initiation of sepsis predicts mortality over 3 days. Shock 17, 463-467. doi: 10.1097/00024382-20020600000004

Russell, J. A. (2006). Management of sepsis. N. Engl. J. Med. 355, 1699-1713. doi: 10.1056/NEJMra043632

Sade-Feldman, M., Kanterman, J., Ish-Shalom, E., Elnekave, M., Horwitz, E., and Baniyash, M. (2013). Tumor necrosis factor- $\alpha$ blocks differentiation and enhances suppressive activity of immature myeloid cells during chronic inflammation. Immunity 38, 541-554. doi: 10.1016/j.immuni. 2013.02.007

Sampedro, G. R., and Bubeck Wardenburg, J. (2017). Staphylococcus aureus in the intensive care unit: are these golden grapes ripe for a new approach? J. Infect. Dis. 215(Suppl. 1): S64-S70. doi: 10.1093/infdis/jiw581

Sander, L. E., Sackett, S. D., Dierssen, U., Beraza, N., Linke, R. P., Müller, M., et al. (2010). Hepatic acute-phase proteins control innate immune responses during infection by promoting myeloid-derived suppressor cell function. J. Exp. Med. 207, 1453-1464. doi: 10.1084/jem.20091474

Sinha, P., Okoro, C., Foell, D., Freeze, H. H., Ostrand-Rosenberg, S., and Srikrishna, G. (2008). Proinflammatory S100 proteins regulate the accumulation of myeloid-derived suppressor cells. J. Immunol. 181, 4666-4675.

Skabytska, Y., Wölbing, F., Günther, C., Köberle, M., Kaesler, S., Chen, K. M., et al. (2014). Cutaneous innate immune sensing of Toll-like receptor 2-6 ligands suppresses $\mathrm{T}$ cell immunity by inducing myeloid-derived suppressor cells. Immunity 41, 762-775. doi: 10.1016/j.immuni.2014.10.009

So, T., Nagashima, H., and Ishii, N. (2015). TNF receptor-associated factor (TRAF) signaling network in CD4(+) T-Lymphocytes. Tohoku J. Exp. Med. 236, 139-154. doi: 10.1620/tjem.236.139

Stieglitz, D., Schmid, T., Chhabra, N. F., Echtenacher, B., Männel, D. N., and Mostböck, S. (2015). TNF and regulatory T cells are critical for sepsis-induced suppression of T cells. Immun. Inflamm. Dis. 3, 374-385. doi: 10.1002/iid3.75 
Tang, B. M., Huang, S. J., and McLean, A. S. (2010). Genome-wide transcription profiling of human sepsis: a systematic review. Crit. Care 14:R237. doi: $10.1186 /$ cc9392

Tebartz, C., Horst, S. A., Sparwasser, T., Huehn, J., Beineke, A., Peters, G., et al. (2015). A major role for myeloid -derived suppressor cells and a minor role for regulatory T cells in immunosuppression during Staphylococcus aureus infection. J. Immunol. 194, 1100-1111. doi: 10.4049/jimmunol. 1400196

Trikha, P., and Carson, W. E. (2014). 3rd. Signaling pathways involved in mdsc regulation. Biochim. Biophys. Acta. 1846, 55-65. doi: 10.1016/j.bbcan.2014.04.003

Tsukamoto, H., Nishikata, R., Senju, S., and Nishimura, Y. (2013). Myeloidderived suppressor cells attenuate TH1 development through IL-6 production to promote tumor progression. Cancer Immunol. Res. 1, 64-76. doi: 10.1158/2326-6066.CIR-13-0030

van Dissel, J. T., van Langevelde, P., Westendorp, R. G., Kwappenberg, K., and Frölich, M. (1998). Anti-inflammatory cytokine profile and mortality in febrile patients. Lancet. 351, 950-953. doi: 10.1016/S0140-6736(05) 60606-X
Vincent, J., Mignot, G., Chalmin, F., Ladoire, S., Bruchard, M., Chevriaux, A., et al. (2010). 5-Fluorouracil selectively kills tumor-associated myeloid-derived suppressor cells resulting in enhanced T cell-dependent antitumor immunity. Cancer Res. 70, 3052-3061. doi: 10.1158/0008-5472.CAN-09-3690

Zhao, X., Rong, L., Zhao, X., Li, X., Liu, X., Deng, J., et al. (2012). TNF signaling drives myeloid-derived suppressor cell accumulation. J. Clin. Invest. 122, 4094-4104. doi: 10.1172/JCI64115

Conflict of Interest Statement: The authors declare that the research was conducted in the absence of any commercial or financial relationships that could be construed as a potential conflict of interest.

Copyright (C) 2018 Ledo, Gonzalez, Poncini, Mollerach and Gómez. This is an openaccess article distributed under the terms of the Creative Commons Attribution License (CC BY). The use, distribution or reproduction in other forums is permitted, provided the original author(s) and the copyright owner(s) are credited and that the original publication in this journal is cited, in accordance with accepted academic practice. No use, distribution or reproduction is permitted which does not comply with these terms. 